\title{
CREEP RUPTURE LIFE AND INTERLAMINAR SHEAR STRENGTH OF WATER-ABSORBED GREEN COMPOSITE WITH PLAIN WOVEN NATURAL FIBER CLOTH
}

\author{
HIDEAKI KATOGI $^{1}$, KENICHI TAKEMURA $^{2} \&$ ATSUHIRO HAYAMORI $^{2}$ \\ ${ }^{1}$ Department of Human Environmental Sciences, Jissen Women's University, Japan \\ ${ }^{2}$ Department of Mechanical Engineering, Kanagawa University, Japan
}

\begin{abstract}
To ensure safety of electric vehicles using green composites, this study examined the interlaminar shear strength, creep rupture strength, and useful life of plain woven jute fiber cloth reinforced polylactic acid after water immersion. The fiber volume fraction of the green composite was $40 \%$. Water absorption tests were conducted of the green composite comprising jute fiber and polylactic acid (PLA). Tensile creep tests of green composite and jute fiber were conducted after water immersion. The maximum stress was $60-90 \%$ of tensile strength. The environmental temperature was room temperature. Short beam testing of double-notched green composite was also conducted after water immersion. Results show the following. When water absorption tests were conducted, the water absorption rates of green composite, jute fiber and PLA at $24 \mathrm{hr}$ were $9 \%, 3.4 \%$ and $0.3 \%$, respectively. The creep rupture strength of $9 \%$ water absorbed green composite was lower than that of non-water-absorbed (non-absorbed) green composite. However, the creep rupture strength of $3.4 \%$ water absorbed jute fiber was slightly higher than that of non-absorbed jute fiber. For maximum stress of $40 \mathrm{MPa}$, the creep rupture life of $9 \%$ water absorbed green composite was much shorter than that of the non-absorbed green composite. Interlaminar shear strength of $9 \%$ water absorbed green composite was lower by $11 \%$ than that of the non-absorbed green composite. Water penetrated to the fiber-resin interface when water absorption test of green composite was conducted until $24 \mathrm{hr}$. Therefore, the interlaminar shear strength, creep rupture life, and green composite strength were decreased mainly because of the decrease of fiber-resin interfacial adhesion as a result of water penetration.
\end{abstract}

Keywords: green composite, creep rupture, interlaminar shear strength, natural fiber, polylactic acid, residual tensile strength, water absorption.

\section{INTRODUCTION}

Green composites incorporating natural fiber and biodegradable polymer have been specifically examined as structural materials used in electric vehicles because the tensile strength of green composites incorporating unidirectional natural fiber approaches that of aluminum [1]. Recently, the LINA electric vehicle was developed using green composites [2]. Many electric vehicles using green composites are expected to be developed. Mechanical properties of green composites and constituent materials have been examined [3]-[13], but green composite creep behavior must be studied further for long-term safety.

Takemura et al. [14] reported the tensile creep behavior of green composites treated with a silane coupling agent. The creep compliance of such treated green composites became lower than that of non-treated green composites at $60^{\circ} \mathrm{C}$. Morreale et al. [15] reported on the creep behavior of green composites incorporating flax fiber cloth. The normalized deformation of green composite incorporating flax fiber cloth at $60^{\circ} \mathrm{C}$ was higher than that of such composites at $40^{\circ} \mathrm{C}$.

Electric vehicles are used in rainy environments. For wider application, many reports have described water absorption properties of green composites [16]-[18]. 
Nam et al. [19] reported the effects of fiber volume fraction on water absorption properties of jute-fiber-reinforced polybutylene succinate (PBS). The water absorption rate of jute-fiber-reinforced PBS during $256 \mathrm{hr}$ increased with increased fiber volume fraction.

The creep behavior of green composites after water immersion must be investigated for long-term safety. Katogi and Takemura [20] examined the creep rupture strength of green composite after water immersion. The creep rupture strength of water-immersed green composite was lower than that of a non-immersed green composite. Furthermore, yarn pullout from the fracture surface of the water immersed green composite was found. For more details, the mechanism of water-absorbed green composites must be investigated under constant loading.

For clarification of related mechanisms, this study examined the creep rupture life and interlaminar shear strength of a green composite after water absorption.

\section{MATERIALS AND MOLDING METHOD}

The matrix was a polylactic acid (PLA) sheet (Ecodear 250-1B01CA; Toray Co. Ltd.). It was reinforced with plain woven jute fiber cloth knitted from spun jute yarn.

Regarding the green composite molding conditions, vacuum compression molding was used with molding pressure was $1.8 \mathrm{MPa}$. The molding time was $10 \mathrm{~min}$. The molding temperature was $190^{\circ} \mathrm{C}$. Subsequently, the mold was cooled to room temperature. The fiber volume fractions of non-absorbed and water-absorbed green composite were $40 \%$.

For molding of the PLA plate, vacuum compression molding was used. The molding pressure was $0.4 \mathrm{MPa}$. The molding time was $10 \mathrm{~min}$. The molding temperature was $190^{\circ} \mathrm{C}$. Subsequently, the mold was cooled to room temperature.

\section{TESTING METHODS}

\subsection{Water absorption tests}

Water absorption tests of green composite and constituent materials were conducted in distilled water. The environmental temperature was room temperature. The maximum immersion time was $24 \mathrm{hr}$. Numbers of specimens for the green composites and PLA were, respectively, five. Green composite specimens were $200 \mathrm{~mm}$ long, $10 \mathrm{~mm}$ wide, and $1.0 \mathrm{~mm}$ thick. The PLA specimens were $50 \mathrm{~mm}$ long, $50 \mathrm{~mm}$ wide, and $4.0 \mathrm{~mm}$ thick.

The jute fiber mass was found using an electronic balance (MSA2.7S-000-DM; Sartorius AG) for 20 specimens. In addition, the masses of 20 specimens were measured together when jute fiber water absorption tests were conducted. Measurements were conducted three times. The jute fiber length was $40 \mathrm{~mm}$.

\subsection{Quasi-static tensile tests}

Before and after water absorption tests, quasi-static tensile tests of green composite were conducted. For residual tensile strength measurements, quasi-static tensile tests of green composites were conducted after creep testing when the loading time was $10^{-2} \mathrm{hr}$ to $10 \mathrm{hr}$. The number of specimens was five. The crosshead speed was $1.0 \mathrm{~mm} / \mathrm{min}$. The environmental temperature was room temperature. The specimen was $200 \mathrm{~mm}$ long, $10 \mathrm{~mm}$ wide, and $1.0 \mathrm{~mm}$ thick. The gauge length was $25 \mathrm{~mm}$.

Quasi-static tensile tests of jute fiber were conducted before and after water absorption tests. As test conditions, the crosshead speed was $1.0 \mathrm{~mm} / \mathrm{min}$. The environmental temperature was room temperature. The gauge length was $10 \mathrm{~mm}$. The number of specimens was 20 . Tensile strengths of non-absorbed and water-absorbed jute fiber were 
calculated using a Weibull distribution. Young's moduli of non-absorbed and waterabsorbed jute fiber were calculated at seven points using the cross-sectional area.

\subsection{Tensile creep test}

Tensile creep tests of non-absorbed and water-absorbed composites were conducted based on Japanese Industrial Standard (JIS) K 7115. The maximum stress was 60-90\% of tensile strength. The environmental temperature was room temperature. The specimens were $200 \mathrm{~mm}$ long, $10 \mathrm{~mm}$ wide, and $1.0 \mathrm{~mm}$ thick.

Tensile creep tests of non-absorbed and water-absorbed jute fibers were conducted. The maximum stress was $60-90 \%$ of tensile strength. The environmental temperature was room temperature. The gauge length was $10 \mathrm{~mm}$.

\subsection{Short beam test}

Short beam tests of double-notched green composite were also conducted before and after water immersion. The environmental temperature was room temperature. The crosshead speed was $1.0 \mathrm{~mm} / \mathrm{min}$. The gauge length was $20 \mathrm{~mm}$. For water absorption rate control, the specimen used for short beam tests was immersed in distilled water for immersion time of $240 \mathrm{hr}$. The number of specimens was five. Fig. 1 presents a schematic drawing of double-notched specimens.

\section{RESULTS AND DISCUSSION}

\subsection{Water absorption properties}

Fig. 2 portrays water absorption properties of the green composite and constituent materials. The water absorption rate of the green composite increased with increased immersion time. However, the water absorption rate of PLA remained almost unchanged with increased immersion time. The water absorption rate of jute fiber increased with increased immersion time until $4 \mathrm{hr}$. Subsequently, scattering of the water absorption rate of jute fiber was slight. Water absorption rates of green composite, jute fiber and PLA at $24 \mathrm{hr}$ were, 9\%, 3.4\% and $0.3 \%$, respectively. One can infer that the water absorption rate of green composite was increased mainly because of the water absorption rate of jute fiber and water penetration into the fiber-resin interface.

\subsection{Tensile properties and interlaminar shear strength}

Fig. 3 presents the tensile strength and Young's modulus of non-absorbed and 9\% water absorbed green composites and jute fiber. The tensile strength and Young's modulus of 9\% water absorbed green composite were lower by $29 \%$ and $35 \%$, respectively, than those of the non-absorbed green composite.

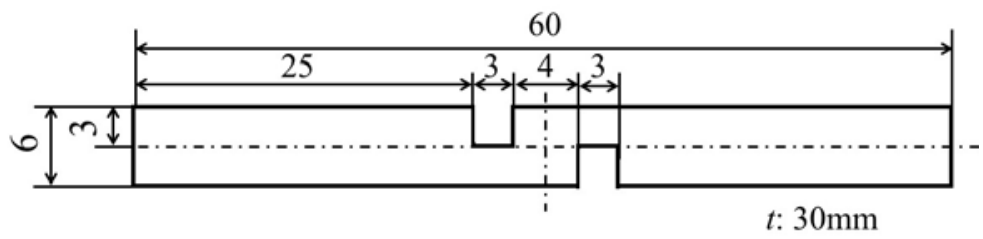

Figure 1: Schematic drawing of double-notched specimen. 

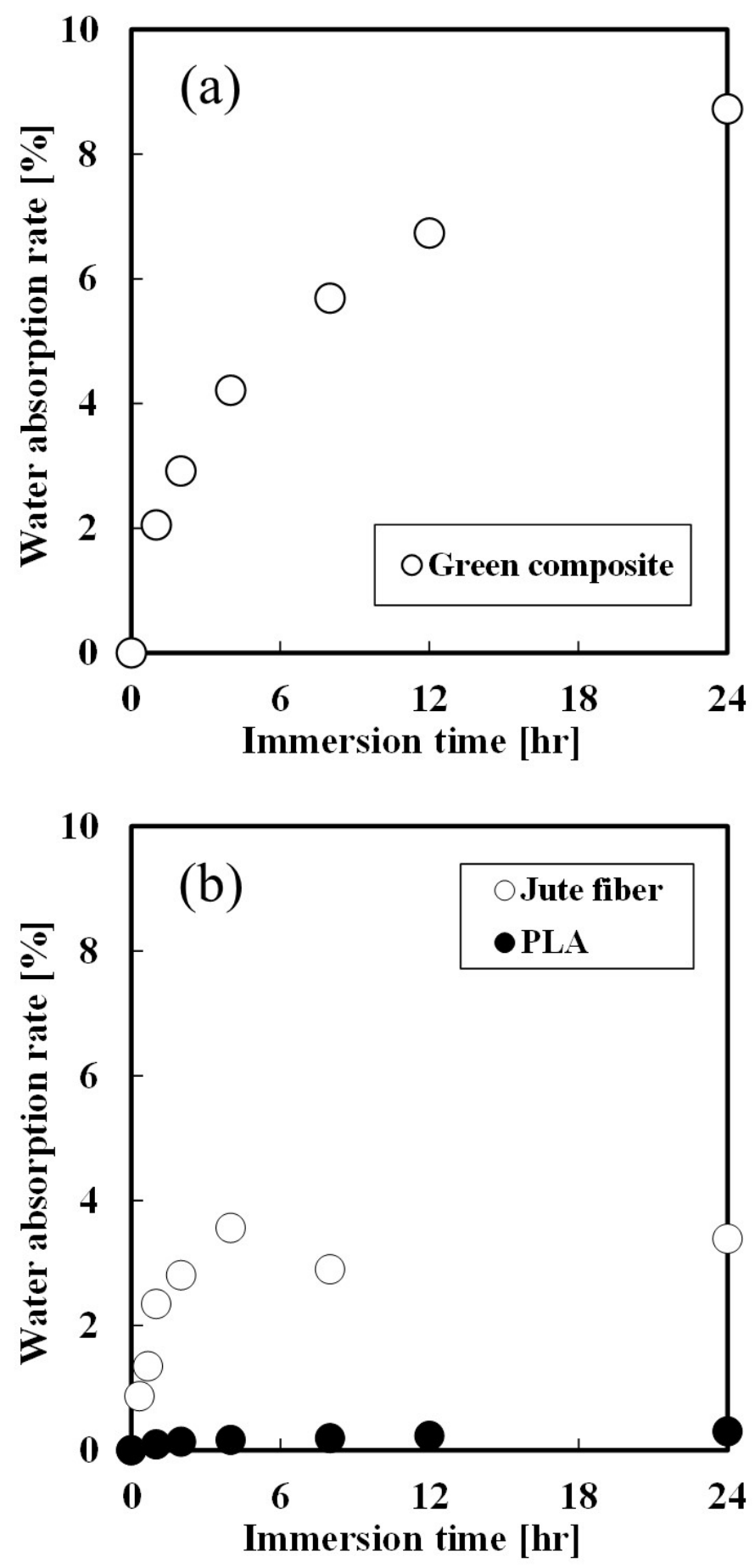

Figure 2: Water absorption properties of green composite and constitutional materials. (a) Green composite; and (b) Jute fiber and PLA. 

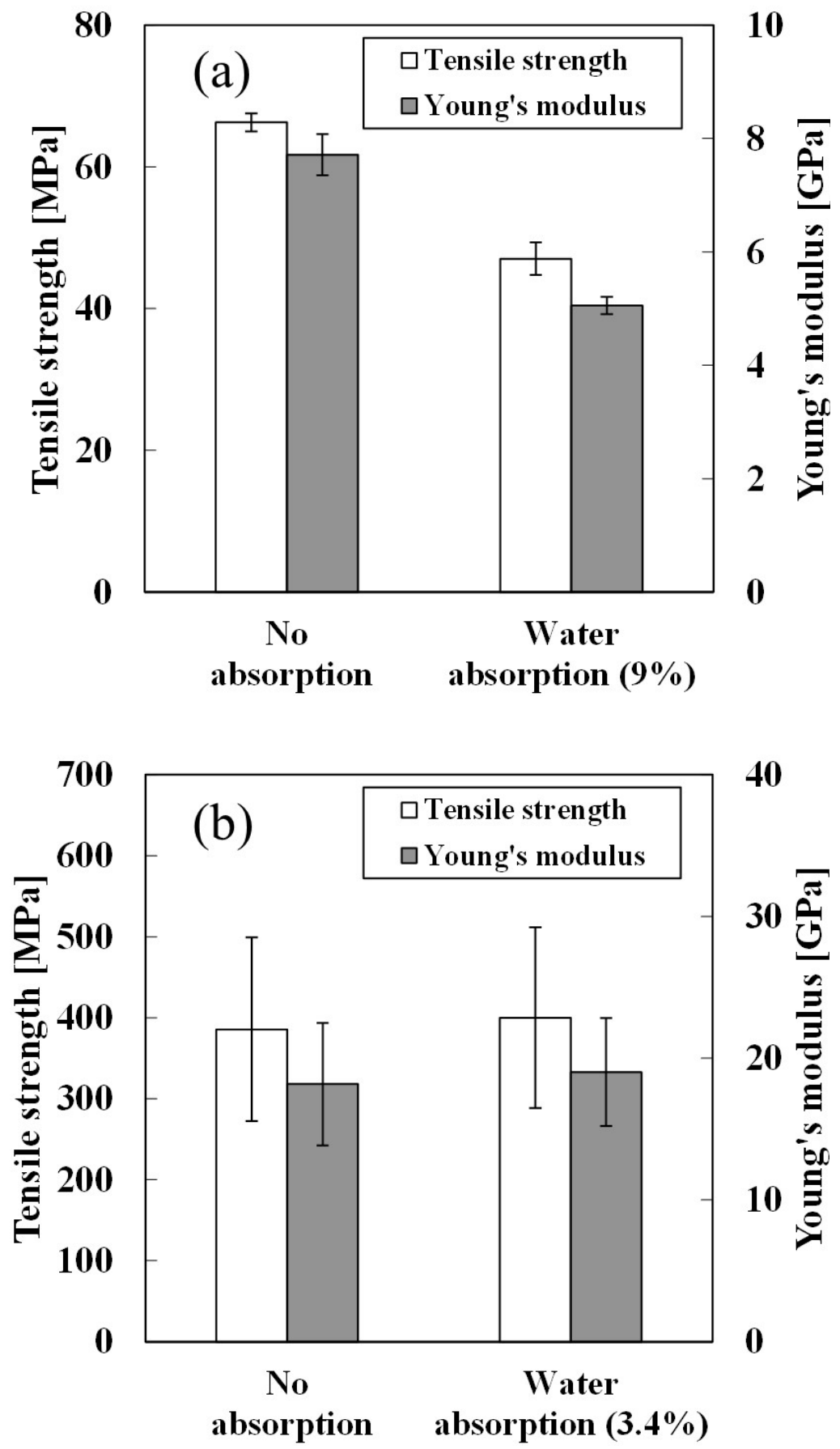

Figure 3: Tensile properties of non-absorbed and water-absorbed green composites and jute fibers. (a) Green composite; and (b) Jute fiber. 
Tensile strengths and Young's moduli of non-absorbed and 3.4\% water absorbed jute fibers remained almost unchanged. Scattering of tensile strengths and Young's moduli of non-absorbed and 3.4\% water absorbed jute fibers was great, but the scattering of tensile strength and Young's modulus of 3.4\% water absorbed jute fiber were generally equal to those of non-absorbed jute fiber. We can infer that the tensile properties of the waterabsorbed green composite were unaffected by the jute fiber water absorption.

Fig. 4 shows interlaminar shear strengths of non-absorbed and water-absorbed green composites. The interlaminar shear strength of $9 \%$ water absorbed green composite was $11 \%$ lower than that of non-absorbed green composite. In this way, the interlaminar shear strength of green composites was decreased because of water penetration into the fiberresin interface.

\subsection{Creep rupture strength and life}

Fig. 5 depicts creep rupture curves of non-absorbed and water-absorbed jute fibers and green composites. Creep rupture strengths of non-absorbed and $9 \%$ water-absorbed green composites decreased with increased loading time. The creep rupture strength of $9 \%$ water absorbed green composite was lower than that of non-absorbed green composite. Creep rupture strengths at $10 \mathrm{hr}$ non-absorbed and $9 \%$ water absorbed green composites were $39 \%$ and $35 \%$, respectively, compared with tensile strengths of non-absorbed and $9 \%$ water absorbed green composites. For maximum stress of $40 \mathrm{MPa}$, the creep rupture life of $9 \%$ water absorbed green composite was much shorter than that of non-absorbed green composites.

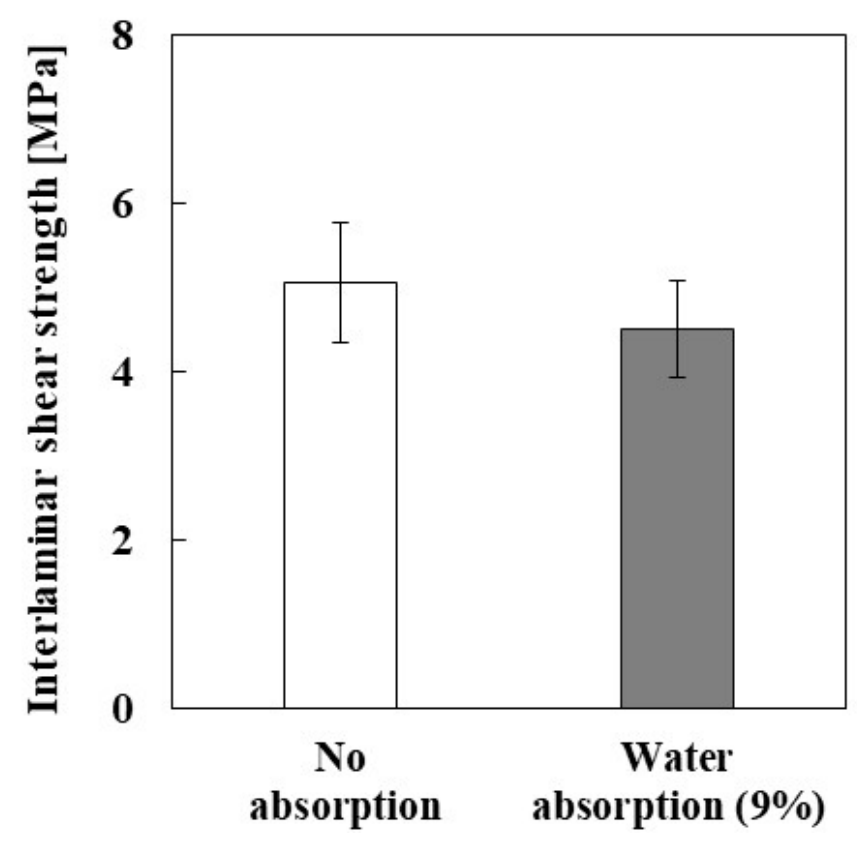

Figure 4: Interlaminar shear strengths of non-absorbed and water-absorbed green composites. 

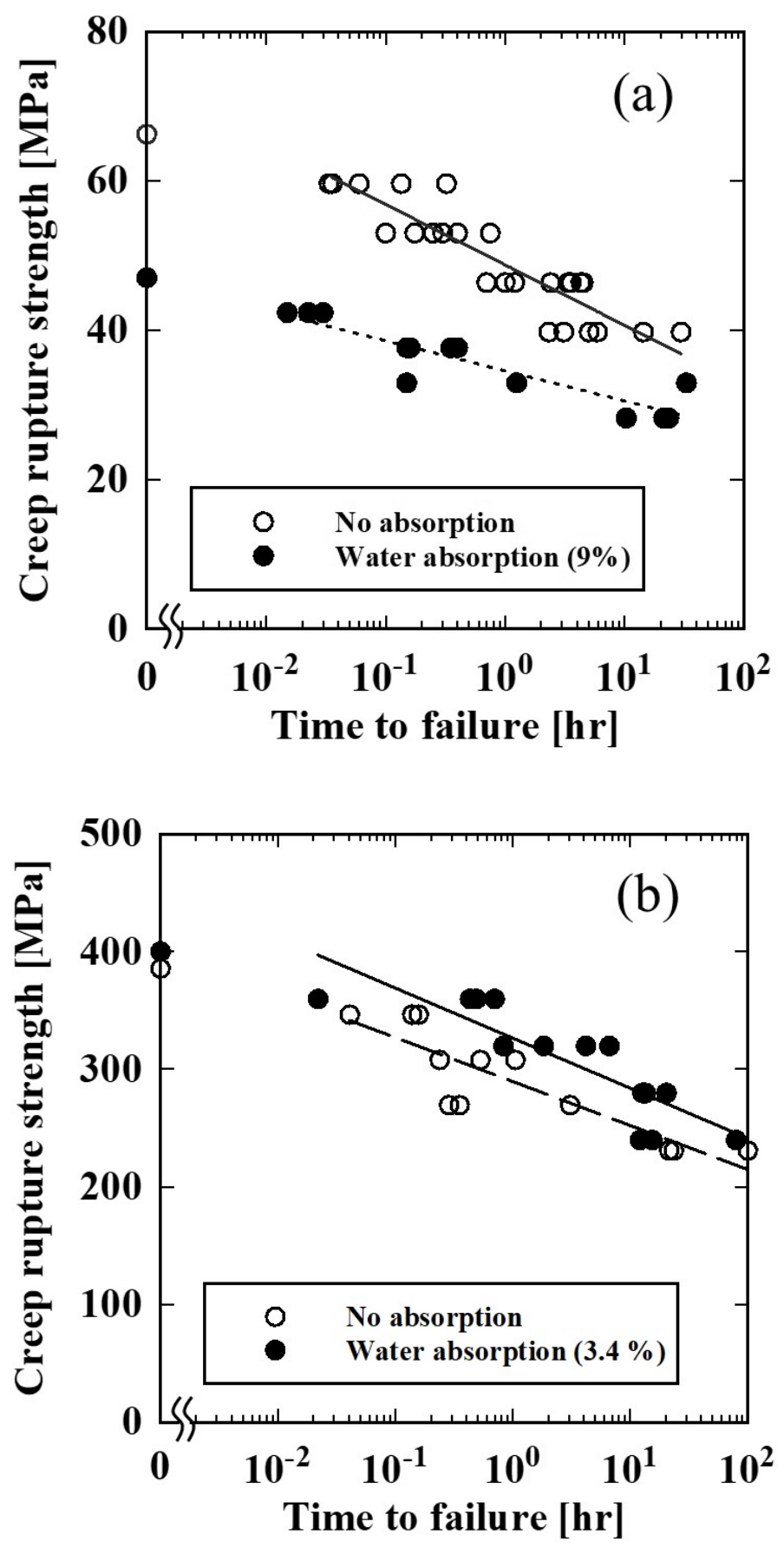

Figure 5: Creep rupture curves of non-absorbed and water-absorbed jute fibers and green composites. (a) Green composite; and (b) Jute fiber. 
Creep rupture strengths of non-absorbed jute fibers decreased with increased loading time. The creep rupture strength of 3.4\% water absorbed jute fiber was slightly higher than that of non-absorbed jute fiber. The creep rupture life of $3.4 \%$ water absorbed jute fiber was slightly longer than that of non-absorbed jute fiber. The jute fiber consists mainly of cellulose, hemicellulose, and lignin [21]. Cellulose and hemicellulose in jute fiber constituent materials have hydrophilicity. Therefore, the creep rupture strength and jute fiber life were affected slightly by water absorption of cellulose and hemicelluloses in jute fiber constituent materials.

Generally, the creep rupture strength of PLA decreases with increased loading time [22]. Nevertheless, the creep rupture strength and life of PLA were unaffected because the water absorption rate of PLA remained almost unchanged. The creep rupture strength and useful life of the green composite were affected by water penetration into the fiber-resin interface.

\subsection{Residual tensile properties of non-absorbed and water-absorbed green composites under constant loading}

Fig. 6 presents residual tensile properties of green composite under constant loading. Tensile strengths of non-absorbed and 9\% water absorbed green composites decreased monotonously with increased loading time. The tensile strength and Young's modulus of a 9\% water absorbed green composite were lower than those of a non-absorbed green composite under all loading times. The Young's moduli of non-absorbed green composite remained almost unchanged under all loading times. Their results implied that tensile strengths of non-absorbed and 9\% water absorbed green composites decreased because of decreased interfacial adhesion between fiber and resin under constant loading. Therefore, the creep rupture strength and life of green composite decreased mainly because of decreased interfacial adhesion between the fiber and resin caused by water penetration.

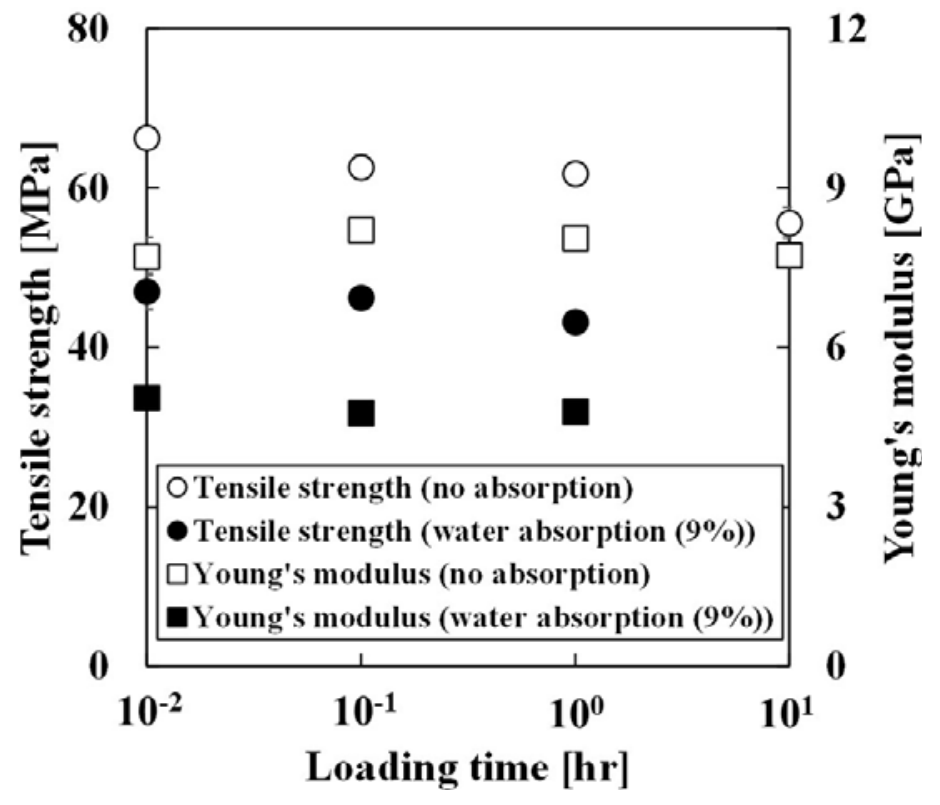

Figure 6: Residual tensile properties of non-absorbed and water-absorbed green composites under constant loading. 


\section{CONCLUSIONS}

This study examined interlaminar shear strength, creep rupture strength, and the useful life of water-absorbed green composites for long-term safety. Water absorption rates of the green composite, jute fiber, and PLA at $24 \mathrm{hr}$ were, respectively, $9 \%, 3.4 \%$ and $0.3 \%$. The creep rupture strength of a $9 \%$ water absorbed green composite was lower than that of nonabsorbed green composite. However, the creep rupture strength of $3.4 \%$ water absorbed jute fiber was slightly higher than that of a non-absorbed jute fiber. With maximum stress of 40 $\mathrm{MPa}$, the creep rupture life of $9 \%$ water absorbed green composite was much shorter than that of the non-absorbed green composite. The interlaminar shear strength of $9 \%$ water absorbed green composite was lower by $11 \%$ than that of a non-absorbed green composite. Tensile strengths of non-absorbed and water-absorbed green composites under constant loading decreased with increased loading time. Therefore, interlaminar shear strength, creep rupture life, and strength of green composite were mainly decreased because of decreased interfacial adhesion at the fiber-resin interface caused by water penetration.

\section{REFERENCES}

[1] Ren, B., Mizue, T., Goda, K. \& Noda, J., Effects of fluctuation of fibre orientation on tensile properties of flax sliver-reinforced green composites. Composite Structures, 94, pp. 3457-3464, 2012.

[2] JEC Group, http://www.jeccomposites.com/knowledge/international-compositesnews/lina-bio-composite-based-car-pla-honeycomb-sandwich-design.

[3] Alvarez, V.A., Kenny, J.M. \& Vazquez, A., Creep behavior of biocomposites based on sisal fiber reinforced cellulose derivatives/starch blends. Polymer Composites, 25 , pp. 280-288, 2004.

[4] Liu, W., Misra, M., Askeland, P., Drzal, L.T. \& Mohanty, A.K., 'Green' composites form soy based plastic and pineapple leaf fiber: fabrication and properties evaluation. Polymer, 46, pp. 2710-2721, 2005.

[5] Takagi, H. \& Asano, A., Effects of processing conditions on flexural properties of cellulose nanofiber reinforced "green" composites. Composites Part A: Applied Science and Manufacturing, 39, pp. 685-689, 2008.

[6] Katogi, H., Shimamura, Y., Tohgo, K. \& Fujii, T., Fatigue behavior of unidirectional jute spun yarn reinforced PLA. Advanced Composite Materials, 21, pp. 1-10, 2012.

[7] Koronis, G., Silva, A. \& Fontul, M., Green composites: A review of adequate materials for automotive applications. Composites Part B: Engineering, 44, pp. 120127, 2013.

[8] Jayavani, S., Deka, H., Varghese, T.O. \& Nayak, S.K., Recent development and future trends in coir fiber-reinforced green polymer composites: review and evaluation. Polymer Composites, 37, pp. 3296-3309, 2016.

[9] Wei, L. \& Mcdonald, A.G., A review on grafting of biofibers for biocomposites. Materials, 9, pp. 303-326, 2016.

[10] Takagi, H, Nakagaito, A.N., Nishimura, K. \& Matsui, T., Mechanical characterisation of nanocellulose composites after structural modification. WIT Transactions on the Built Environment, vol. 166, WIT Press: Southampton and Boston, pp. 335-341, 2016.

[11] Tanaka, K., Shiga, T. \& Katayama, T., Fabrication of hydroxyapatite/PLA composite nanofiber by electrospinning. WIT Transactions on the Built Environment, vol. 166, WIT Press: Southampton and Boston, pp. 371-379, 2016. 
58 High Performance and Optimum Design of Structures and Materials III

[12] Katogi, H., Takemura, K. \& Akiyama, M., Residual tesile property of pain woven jute fiber/poly(lactic acid) green composites during thermal cycling. Materials, 9, pp. 573-583, 2016.

[13] Ullah, A.M.M.S., Shahinur, S. \& Haniu, H., On the mechanical properties and uncertainties of jute yarn. Materials, 10, pp. 450-464, 2017.

[14] Takemura, K., Takada, Y. \& Katogi, H., Effect of treatment using silane coupling agent on creep properties of jute-fiber-reinforced composites. WIT Transactions on the Built Environment, vol. 124, WIT Press: Southampton and Boston, pp. 417-424, 2012.

[15] Morreale, M., Mistretta, M.C. \& Fiore, V., Creep behavior of poly(lactic acid) based biocomposites. Materials, 10, pp. 395-407, 2017.

[16] Plackett, D., Andersen, T.L., Pedersen, W.B. \& Nielsen, L., Biodegradable composites based on L-polylactide and jute fibres. Composite Science and Technology, 63, pp. 1287-1296, 2003.

[17] Cyras, V.P., Manfredi, L.B., Ton-That, M.T. \& Vazquez, A., Physical and mechanical properties of thermoplastic starch/montmorillonite nanocomposite films. Carbohydrate Polymers, 73, pp. 55-63, 2008.

[18] Islam, M.S., Pickering, K.L. \& Foreman, N.J., Influence of accelerated ageing on the physic-mechanical properties of alkali-treated industrial hemp fibre reinforced poly(lactic acid) (PLA) composites. Polymer Degradation and Stability, 95, pp. 59$65,2010$.

[19] Nam, T.H., Ogihara, S., Nakatani, H., Kobayashi, S. \& Song, J.I., Mechanical and thermal properties and water absorption of jute-fiber-reinforced poly(butylene succinate) biodegradable composites. Advanced Composite Materials, 21, pp. 241$258,2012$.

[20] Katogi, H. \& Takemura, K., Creep rupture of water-absorbed green composite. WIT Transactions on Engineering Sciences, vol. 116, WIT Press: Southampton and Boston, pp. 281-288, 2017.

[21] Ray, D. \& Sarkar, B.K., Characterization of alkali-treated jute fibers for physical and mechanical properties. Journal of Applied Polymer Science, 80, pp. 1013-1020, 2001.

[22] Ooi, K. \& Ohgi, J., Elongation behavior of polylactic acid under creep loading. Proceedings of the 59th JSMS Annual Meeting, pp. 17-18, 2010 (in Japanese). 